\title{
Role of tamoxifen and danazol in mastalgia: prospective controlled trial
}

\author{
Prashant Gupta, Vandana Verma, Rekha Gupta, Anil Kumar, Somendra Pal Singh*, \\ Umesh K. Gupta, Shesh Kumar, Mohit Gupta, Praveen Singh, Swadeep Shrivastava, \\ Santosh K. Gupta
}

Department of Surgery, UP RIMS \& R, Saifai, Etawah, UP, India

Received: 06 March 2016

Revised: 10 March 2016

Accepted: 12 March 2016

\section{*Correspondence:}

Dr. Somendra Pal Singh,

E-mail: somendrachauhan@ hotmail.com

Copyright: (C) the author(s), publisher and licensee Medip Academy. This is an open-access article distributed under the terms of the Creative Commons Attribution Non-Commercial License, which permits unrestricted non-commercial use, distribution, and reproduction in any medium, provided the original work is properly cited.

\section{ABSTRACT}

Background: Mastalgia is one of the most common presenting symptoms of benign breast diseases, which may be cyclical or continuous. Mastalgia is the commonest breast symptom presenting in surgical clinics. Mastalgia is a symptom of great importance to those who experience it. These have been tendencies to ignore the condition, however, the relative reluctance of the patient due to the nature of disease and the antipathy towards the disease that has prevailed in our society has led to little scope of therapy. Works of some senior have added to misery of such patients. To study role of tamoxifen and danazol in mastalgia is the main objective of the present study.

Methods: This was a prospective randomized control trial done in outpatient department (OPD) of Department of Surgery, UP, RIMS \& R, Saifai, Etawah from July 2014-December 2015 i.e. 18 months. All patients coming to OPD in first 15 days of month s were given danazol $200 \mathrm{mg} /$ day for a period of two months. All those coming in next half were treated with tamoxifen $20 \mathrm{mg} /$ day for two months.

Results: Danazol when used is effective in achieving complete or partial response in $70.83 \%$ of cyclic mastalgia when given in dose of $200 \mathrm{mg} /$ day for two months. However $29.17 \%$ patients did not respond to it. Tamoxifen when used is effective in achieving complete or partial response in $66.67 \%$ of cyclical mastalgia when given in dose of 20 $\mathrm{mg} /$ day for two months. However $33.33 \%$ patients did not respond to it.

Conclusions: Our study shows danazol treatment is more effective in treatment of cyclic mastalgia. Non cyclic mastalgia is difficult type to be cured by drug therapy.

Keywords: Cyclic mastalgia, Non cyclic mastalgia, Danazol, Tamoxifen

\section{INTRODUCTION}

Breast pain or mastalgia is one of the most common benign conditions of the breast. The pattern and severity of pain can be assessed by breast pain chart. Mastalgia may be cyclic or non-cyclic, intermittent or constant, localized or diffuse. ${ }^{1,2}$ Cyclical mastalgia is defined as breast pain with either only premenstrual exacerbation or pain throughout the month with premenstrual exacerbation. Non-cyclical mastalgia is defined as intermittent or continuous breast pain without premenstrual exacerbation and no obvious source of musculoskeletal disease. ${ }^{3,4}$ Non-cyclical mastalgia can be true i.e arising from breast tissue or it can arise from chest wall e.g. Tietze's syndrome and lateral chest wall pain during luteal phase of menstruation, cell proliferation of ductolobular tissue and interstitial fluid increase result in up to $15 \%$ increase in breast size and volume. ${ }^{5,6}$ This increase in breast tissue volume results in pressure on pain nerve endings causing premenstrual pain. Just prior to menstruation the estrogen and progesterone levels fall with reducing cellular proliferation in the early follicular phase and consequent relief of pain and engorgement. ${ }^{7,8}$ 
The mastalgia may be caused by,

- Increased estrogen secretion from ovary

- Deficient progesterone production

- Increased Prolactin secretion

\section{Aims \& objectives}

To study role of tamoxifen and danazol in mastalgia.

\section{METHODS}

This was a prospective randomized control trial done in outpatient department (OPD) of Department of Surgery, UP RIMS\&R, Saifai, Etawah from July 2014December 2015 i.e. 18 months.

The patients was provided with a detailed printed information sheet ( in Hindi or English depending on the language understood by her) to explain about benign nature of breast pain, the currently available therapy with side effects, the potential benefits of tamoxifen and danazol . All patients coming to OPD in first 15 Days of month s were given danazol $200 \mathrm{mg} /$ day for a period of two months. All those coming in next half were treated with tamoxifen $20 \mathrm{mg} /$ day for two months.

Patients were called to OPD on every $15^{\text {th }}$ day to assess the response and also to check that the patient was appropriately following the given treatment. After two months of therapy the score was assessed.

Danazol: $200 \mathrm{mg} /$ day

Tamoxifen: $20 \mathrm{mg} /$ day

Response was assessed using the same score after 2 month of therapy.

Side effects during the course of therapy were recorded. Relapses that are defined as reoccurrence of troubling mastalgia within 6 month after discontinuation of therapy were recorded and patient was treated with same drug to which he earlier responded.

All women in reproductive age group with regular menses having mastalgia was recruited in the study.

\section{Inclusion criteria}

All women with mastalgia with VAS score $\geq 3$ lasting for more than 7 days per cycle will be included after signing a consent form.

\section{Exclusion criteria}

1. Patients with polycystic ovarian diseases and uterine cervical hyperplasia.

2. First six months of Lactation and pregnancy.

3. Patients who are not giving consent.
4. Past history of breast carcinoma or family history of breast carcinoma

5. Patient who are planning for pregnancy.

After an initial clinical assessment and breast imaging with ultrasound (and mammogram for cases above age 35 years) to exclude any lump or mammary ductal disease. Patients will be asked to keep a record of their breast pain in a "pain diary". In this diary patient will be filling the occurrence of pain on a day to day basis. The time of menses will also mark on pain diary. The severity of mastalgia will be assessed by visual analogue scale score ranging from $0-10$. Zero (0) indicating no pain and 10 indicating very severe pain.

\section{RESULTS}

A total of 94 patients complaining of severe breast pain were examined during the span of 18 month i.e. July 2014-December 2015. Out of this 72 cases were deemed fit for study as they fulfilled the criteria mentioned in material and method.

Out of the remaining 22, 2 had infiltrating duct carcinoma, 7 had tubercular mastitis, 3 had galactocele, 2 had undergone hysterectomy, 4 were pregnant or were lactating and unwilling to stop breast feeding. 3 patients did not come on follow up, one had cysticercosis and one had ductectasia. These patients were left from the study.

Table 1: Age distribution in mastalgia.

\begin{tabular}{|lll|}
\hline Age group & Number & Percentage \\
\hline $15-25$ & 13 & $18.06 \%$ \\
\hline $26-35$ & 27 & $37.50 \%$ \\
\hline $36-45$ & 28 & $38.88 \%$ \\
\hline $46-55$ & 4 & $05.56 \%$ \\
\hline Total & $\mathbf{7 2}$ & $\mathbf{1 0 0 \%}$ \\
\hline
\end{tabular}

Mean age of the patients selected for the study was 30.5 years. We found commonest age group presenting with mastalgia was between 36-45 (38.88\%) and almost $75 \%$ patients were in third to fifth decade of life.

We observed that cyclical mastalgia was the commonest type of breast pain. Constituting $66.67 \%$ of total were as non-cyclical mammary causes constituted $27.78 \%$ of total causes of pain. Extra mammary pain was reported in $05.55 \%$ cases.

Table 2: Percentage of cyclical and non-cyclical mastalgia.

\begin{tabular}{|c|c|c|}
\hline Type & Numbers & Percentage \\
\hline Cyclical mastalgia & 48 & $66.67 \%$ \\
\hline Non-cyclical mastalgia & 20 & $27.78 \%$ \\
\hline Extra mammary pain & 04 & $05.55 \%$ \\
\hline Total & 72 & 100 \\
\hline
\end{tabular}


Table 3: Result of drug therapy for cyclical mastalgia.

\begin{tabular}{|llll|}
\hline Drug & N & Response & No response \\
\hline Danazol & 24 & $17(70.83 \%)$ & $7(29.17 \%)$ \\
\hline Tamoxifen & 24 & $16(66.67 \%)$ & $8(33.33 \%)$ \\
\hline Total & $\mathbf{4 8}$ & & \\
\hline
\end{tabular}

Danazol when used is effective in achieving complete or partial response in $70.83 \%$ of cyclic mastalgia when given in dose of $200 \mathrm{mg} /$ day for two months. However $29.17 \%$ patients did not respond to it. Tamoxifen when used is effective in achieving complete or partial response in $66.67 \%$ of cyclical mastalgia when given in dose of 20 $\mathrm{mg}$ /day for two months. However $33.33 \%$ patients did not respond to it.

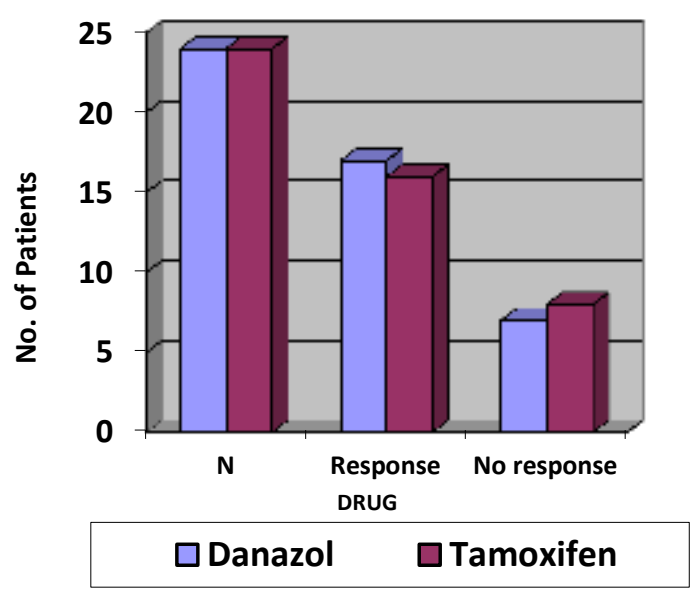

Figure 1: Bar diagram showing response to danazol and tamoxifen in cyclical mastalgia.

Table 4: Result of drug therapy for non-cyclical mastalgia.

\begin{tabular}{|llll|}
\hline Drug & N & Response & No Response \\
\hline Danazol & 10 & $3(30 \%)$ & $7(70 \%)$ \\
\hline Tamoxifen & 10 & $4(40 \%)$ & $6(60 \%)$ \\
\hline
\end{tabular}



Figure 2: Bar diagram showing response to danazol and tamoxifen in non-cyclical mastalgia.
Danazol was effective in achieving useful response in only $30 \%$ cases with non-cyclical mastalgia as compared to tamoxifen which was able to achieve response in $40 \%$ cases. Non-cyclical mastagia was a difficult type to cure.

\section{DISCUSSION}

The exact cause of mastalgia is still unknown. Severe mastalgia can however disrupt normal life by interfering with sleep, relationship with husband and children and may also affect occupation of working women. Severe cyclical mastalgia runs a long course especially if it begins in third or fourth decade of life. It may last the entire menstrual age of female and the only chance of relief may be menopause. Its clear relationship to the menstrual cycle has pointed to the female sex hormones, being responsible with perhaps an altered sensitivity of the breast as target organ. This type is amenable to hormonal manipulation.

Non cyclic mastalgia has a lesser response rate to hormonal preparation as compared to cyclical mastalgia and several modalities may be tried before a response is seen. Surgery does not seem to provide any significant advantage as the pain may persist even after the operation hence surgery should be resorted only in limited cases specially for those patients who themselves insist for surgery. Extramammary non-cyclical mastalgia require NSAIDs or lignocaine injection as they do not respond to hormonal therapy.

Srivastava A et $\mathrm{al}^{6}$ in a study comparing bromocriptine, danazol, evening primrose oil (EPO) and tamoxifen with placebo found that bromocriptine followed by danazol was effective for pain relief in mastalgia which supports finding of our study that danazol is effective in cyclic mastalgia.

Saied GM, Kamel RM, Dessouki $\mathrm{N}^{9}$ in their study found that bromocriptine with evening rose of primrose oil was more effective in cyclic mastalgia. In our study we also found that both danazol and tamoxifen was more effective in cyclic mastalgia.

Aydin $\mathrm{Y}$ et $\mathrm{al}^{10}$ in their study compared the effectiveness and side effects of cabergoline with bromocriptine for the symptomatic treatment of cyclic mastalgia as a part of the premenstrual syndrome. The positive response rates to treatment were similar (bromocriptine $66.6 \%$ and cabergoline $68.4 \%$ ). In our study response to danazol and tamoxifen was $70.83 \%$ and $66.67 \%$ which was almost comparable in cases of cyclical mastalgia.

S. Fentiman, M. Caleffi UK et.al ${ }^{11}$ conducted a controlled trial in which 60 women with mastalgia were randomly allocated to receive tamoxifen at a dosage of either $10 \mathrm{mg}$ or $20 \mathrm{mg}$ daily for either 3 or 6 months. Pain relief was achieved in 90 per cent of those receiving 10 $\mathrm{mg}$ daily and 86 per cent of those given $20 \mathrm{mg}$ daily. 


\section{CONCLUSION}

Our study shows danazol treatment is more effective in treatment of cyclic mastalgia. Non cyclic mastalgia is difficult type to be cured by drug therapy.

Funding: No funding sources Conflict of interest: None declared

Ethical approval: The study was approved by the institutional ethics committee

\section{REFERENCES}

1. Ader DN, South-Paul J, Adera T, Deuster PA. Cyclical mastalgia: prevalence and associated health and behavioural factors. J Psychocsom Obstet Gynecol. 2001;22:71-6.

2. Kessel B. Premenstrual syndrome: Advances in diagnosis and treatment. Obstet Gynecol Clin North Am. 2000;27:625-39.

3. Goodwin PJ, Miller A, Del Giudice ME, Ritchie K. Breast health and associated premenstrual symptoms in women with severe cyclic mastopathy. Am J Obstet Gynecol. 1997;176:998-1005.
4. Ader DN, Browne MW. Prevalence and impact of cyclic mastalgia in a United States clinic-based sample. Am J Obstet Gynecol. 1997;177:126-32.

5. Wisbey JR, Kumar S, Mansel RE, Preece PE, Pye JK, Hughes LE. Natural history of breast pain. Lancet. 1983;2:672-4.

6. Srivastava A, Mansel RE, Arvind N, Prasad K, Dhar A, Chabra A. Evidence-based management of mastalgia: a meta-analysis of randomised trials. Breast. 2007;16:503-12.

7. Mansel RE, Goyal A, Preece P, Leinster S, Maddox $\mathrm{PR}$, Gateley $\mathrm{C}$ et al. European randomized, multicenter study of goserelin (Zoladex) in the management of mastalgia. Am J Obstet Gynecol. 2004;191:1942-9.

8. Pye JK, Mansel RE, Hughes LE. Clinical experience of drug treatments for mastalgia. Lancet. 1985;2:373-7.

9. Saied GM, Kamel RM, Dessouki N. Tanzan Health Res Bull. 2007;9(3):196-201.

10. Aydin Y, Atis A, Kaleli S, Uludağ S, Goker N. Eur J Obstet Gynecol Reprod Biol. 2010;150(2):203-6.

11. Fentiman IS, Powles TJ. Tamoxifen and benign breast conditions, the end or just the beginning? Lancet. 1987;2:1070-71.

Cite this article as: Gupta P, Verma V, Gupta R, Kumar A, Singh SP, Gupta UK, Kumar S, Gupta M, Singh P, Shrivastava S, Gupta SK. Role of tamoxifen and danazol in mastalgia: prospective controlled trial. Int Surg J 2016;3:553-6. 